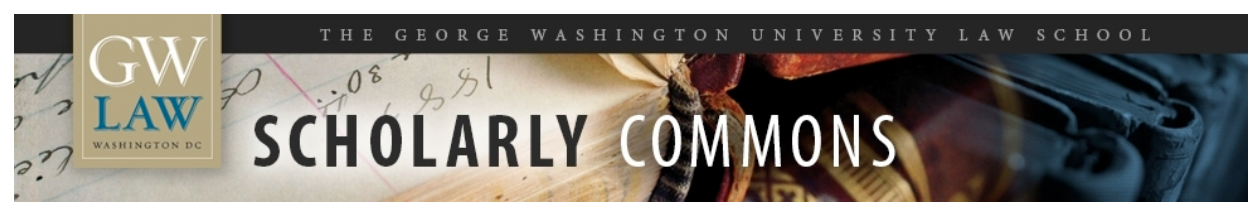

\title{
Who Fears the HPV Vaccine, Who Doesn't, and Why? An Experimental Study of the Mechanisms of Cultural Cognition
}

\author{
Donald Braman \\ George Washington University Law School, dbraman@law.gwu.edu
}

Dan M. Kahan

Geoffrey L. Cohen

Paul Slovic

John Gastil

Follow this and additional works at: https://scholarship.law.gwu.edu/faculty_publications

Part of the Law Commons

\section{Recommended Citation}

Donald Braman et. al., Who Fears the HPV Vaccine, Who Doesn't, and Why? An Experimental Study of the Mechanisms of Cultural Cognition, 34 Law \& Hum. Behav. 501 (2008).

This Article is brought to you for free and open access by the Faculty Scholarship at Scholarly Commons. It has been accepted for inclusion in GW Law Faculty Publications \& Other Works by an authorized administrator of Scholarly Commons. For more information, please contact spagel@law.gwu.edu. 
final published in Law \& Human Behavior, 34: 501-16 (2010)

Who Fears the HPV Vaccine, Who Doesn't, and Why?

An Experimental Study of the Mechanisms of Cultural Cognition

\author{
Dan M. Kahan, Yale Law School \\ Donald Braman, George Washington Law School \\ Geoffrey L. Cohen, Stanford University \\ John Gastil, University of Washington \\ Paul Slovic, Decision Research
}

Author Note. Research for this paper was funded by the National Science Foundation, Grant SES 0621840, and the Oscar M. Ruebhausen Fund at Yale Law School. We would like to thank Katherine Bell for editorial assistance. Correspondence concerning this article should be addressed to Dan M. Kahan, Yale Law School, PO Box 208215, New Haven, CT 06520. Email: dan.kahan@yale.edu. 


\begin{abstract}
The cultural cognition thesis holds that individuals form risk perceptions that reflect their commitments to contested views of the good society. We conducted a study that used the dispute over mandatory HPV vaccination to test the cultural cognition thesis. Although public health officials have recommended that all girls aged 11 or 12 be vaccinated for HPV - a sexuallytransmitted virus that causes cervical cancer-political controversy has blocked adoption of mandatory school-enrollment vaccination programs in all but one state. An experimental study of a large sample of American adults $(N=1,538)$ found that cultural cognition generates disagreement about the risks and benefits of the vaccine through two mechanisms: biased assimilation, and the credibility heuristic. We discuss theoretical and practical implications.
\end{abstract}


The advent of the human-papillomavirus (HPV) vaccine was widely heralded as a "major public health breakthrough" (Kaufman, 2006, June 9, p. A1). that would "eventually save thousands of lives each year in the United States" (Harris, 2006, p. A1). Transmitted by sexual contact, HPV is the leading (likely the sole) cause of cervical cancer. It is estimated that as many as $45 \%$ of women in their early twenties have been infected by it (Dunne et al, 2007). Shortly after the FDA awarded "fast track" approval to the vaccine, the Center for Disease Control recommended that it be administered to all girls (no vaccine is currently approved for males) at age 11 or 12 , before they are likely to have been exposed to the virus, at which point the vaccine becomes ineffective (CDC, 2006). Public health advocates-financed conspicuously by Merck \& Co., manufacturer of the vaccine- thereafter initiated a campaign to secure enactment of mandatory vaccination laws like those that require school children to be immunized against mumps, measles, rubella, and other childhood diseases (Saul \& Pollack, 2007).

Nevertheless, the proposal for mandatory vaccination of schoolgirls has been mired in intense controversy. The vaccine admittedly fails to protect against $30 \%$ of the strains of HPV that cause cervical cancer, and critics question its reported effectiveness against the remainder. They also worry about the likelihood that vaccination will have unanticipated (or undisclosed) adverse side-effects (Merck \& Co., they point out, also manufactured Vioxx). Debate rages, too, over the possibility that vaccinated girls and young women, lulled into a false sense of security, will engage in greater amounts promiscuous and unprotected sex, thereby increasing their risk of pregnancy and other STDs (Alliance for Human Research Protection, 2007; Gibbs, 2006).

Although the public argument features competing empirical claims, the battle lines are decidedly political. Commentaries promoting the case for mandatory vaccination appear in recognizably liberal media outlets like the New York Times (Brody, 2007), ones resisting it in 
familiar conservative ones like the Wall Street Journal (Carreyrou, 2006). Women's advocacy groups lobby for mandatory vaccination programs (NOW, 2006), and traditional religious ones against them (Focus on the Family, 2007).

As a result of such conflict, the campaign to implement mandatory school vaccination has faltered, if not failed. One program established by order of the Governor of Texas was repealed by the state legislature. Another program was passed by the New Mexico legislature but thereafter vetoed by the Governor. Numerous states have considered and rejected mandatory vaccination programs. To date only Virginia (site of a proposed Merck plant to manufacture the vaccine) and the District of Columbia have adopted ones (National Conference of State Legislatures 2009; Rosenthal, 2008). ${ }^{1}$

What explains the HPV-vaccination controversy? Are those on both sides genuinely uncertain about whether mandatory school vaccination would promote the health of girls and young women? Or are the positions they take — against but also for the mandatory vaccinationan expression of moral or political values unrelated to the efficacy of the vaccine?

One account of risk perception implies that the answer might well be a distinctive mixture of both of these explanations. The cultural theory of risk asserts that individuals selectively attend to risks and related facts in a way that reflects and reinforces their "cultural worldviews," or preferences about how society should be organized (e.g. Douglas \& Wildavsky, 1982; Wildavsky \& Dake, 1990). If this process is at work in the HPV vaccine debate, those on both sides are advancing the positions that they honestly believe promote the health of girls and young women. Yet the reason that they hold those particular beliefs is the congeniality of one or another set of risk perceptions to their preferred vision of the good society. 
This paper uses the debate over mandatory HPV vaccination to test the cultural theory of risk. It seeks to determine, moreover, not just whether individuals' cultural worldviews affect their risk perceptions, but, if they do, why. What are the psychological dynamics - the mechanisms of cultural cognition - that connect values to empirical beliefs of this sort? In an experimental study involving some 1,500 subjects, we found evidence that two mechanismsbiased assimilation of information, and source credibility — do indeed seem to dispose persons of diverse values to adopt conflicting stances on the public health consequences of the proposal for mandatory HPV vaccination. We begin with a discussion of the theoretical background of the study before describing its design and reporting its results, and we conclude with some observations about its theoretical and practical implications

\section{Theoretical Background: Heuristics, Culture, and Risk}

The study of risk perception addresses a puzzle. How do people_-particularly ordinary citizens who lack not only experience with myriad hazards but also the time and expertise necessary to make sense of complex technical data-form positions on the dangers they face and what they should do about them?

Social psychology has made well-known progress toward answering this question. People (not just lay persons, but quite often experts too) rely on heuristic reasoning to deal with risk and uncertainty generally. They thus employ a range of "mental shortcuts": when gauging the danger of a putatively hazardous activity (the possession, say, of a handgun, or the use of nuclear power generation), they consult a mental inventory of recalled instances of misfortunes involving it, give special weight to perceived authorities, and steer clear of options that could improve their situation but that also involve the potential to make them worse off than they are at present ("better safe, than sorry”) (Kahneman, Slovic, \& Tversky, 1982; Slovic, 2000; Margolis, 1996). 
They also employ faculties and styles of reasoning — most conspicuously affective ones informed by feelings such as hope and dread, admiration and disgust — that make it possible for them to respond rapidly to perceived exigency (Slovic, Finucane, Peters \& MacGregor, 2004).

To be sure, heuristic reasoning of this sort can lead to mistakes, particularly when they crowd out more considered, systematic forms of reasoning (Sunstein, 2005). But they are adaptive in the main (Slovic et al, 2004).

As much as this account has enlarged our knowledge, it remains incomplete. In particular, a theory that focuses only on heuristic reasoning fails to supply a cogent account of the nature of political conflict over risk (Kahan, Slovic, Braman \& Gastil, 2006). Citizens disagree, intensely, over a wide range of personal and societal hazards. If the imprecision of heuristic reasoning accounted for such variance, we might expect such disagreements to be randomly distributed across the population or correlated with personal characteristics (education, income, community type, exposure to news of particular hazards, and the like) that either plausibly related to one or another heuristic or that made the need for heuristic reasoning less necessary altogether. By and large, however, this is not the case. Instead, a large portion of the variance in risk perception coheres with membership in groups integral to personal identity, such as race, gender, political party membership, and religious affiliation (e.g. Slovic, 2000, p. 390; Kahan \& Braman, 2006). Whether the planet is overheating; whether nuclear wastes can be safely disposed of; whether genetically modified foods are bad for human health—these are cultural issues in American society every bit as much as whether women should be allowed to have abortions and men should be allowed to marry other men (Kahan, 2007). Indeed, as unmistakably cultural in nature as these latter disputes are, public debate over them often 
features competing claims about societal risks and benefits, and not merely competing values (e.g. Siegel, 2007; Pollock, 2005).

This is the part of the risk-perception puzzle that the cultural theory of risk is distinctively concerned with (Douglass \& Wildavsky, 1982). According to that theory, individuals conform their perceptions of risk to their cultural evaluations of putatively dangerous activities and the policies for regulating them. Thus, persons who subscribe to an "individualist" worldview react dismissively to claims of environmental and technological risks, societal recognition of which would threaten markets and other forms of private ordering. Persons attracted to "egalitarian" and "communitarian" worldviews, in contrast, readily credit claims of environmental risk: they find it congenial to believe that commerce and industry, activities they associate inequity and selfishness, cause societal harm. Precisely because the assertion that such activities cause harm impugns the authority of social elites, individuals of a "hierarchical worldview" are (in this case, like individualists) risk skeptical (Rayner, 1992).

Researchers have furnished a considerable body of empirical support for these patterns of risk perception (Dake, 1991; Jenkins-Smith, 2001; Ellis \& Thompson, 1997; Peters \& Slovic, 1996; Peters, Burriston \& Mertz, 2004; Kahan, Braman, Gastil, Slovic \& Mertz, 2007). Such studies have found that cultural worldviews explain variance more powerfully than myriad other characteristics, including socio-economic status, education, and political ideology, and can interact with and reinforce the effect of related sources of identity such as race and gender.

Although one could see a rivalry between culture theory and the heuristic model (Marris, Langford, O'Riordan 1998; Douglas, 1997), it is unnecessary to view them as mutually exclusive. Indeed, one conception of the cultural theory—which we will call the cultural cognition thesis ((Kahan, Braman, Monahan, Callahan \& Peters, in press; Kahan, Slovic, Braman 
\& Gastil, 2006) - seeks to integrate them. Culture theorists have had relatively little to say about exactly how culture shapes perceptions of risk. ${ }^{2}$ Cultural cognition posits that the connection is supplied by conventional heuristic processes, or at least some subset of them (DiMaggio, 1997). On this account, heuristic mechanisms interact with cultural values: People notice, assign significance to, and recall the instances of misfortune that fit their values; they trust the experts whose cultural outlooks match their own; they define the contingencies that make them worse off, or count as losses, with reference to culturally valued states of affairs; they react affectively toward risk on the basis of emotions that are themselves conditioned by cultural appraisals — and so forth. By supplying this account of the mechanisms through which culture shapes risk perceptions, cultural cognition not only helps to fill a lacuna in the cultural theory of risk. It also helps to complete the heuristic model by showing how one and the same heuristic process (whether availability, credibility, loss aversion, or affect) can generate different perceptions of risk in people with opposing outlooks.

The proposition that moral evaluations of conduct shape the perceived consequences of such conduct is not unique to the cultural cognition thesis. Experimental study, for example, shows that negative affective responses mediate between moral condemnation of "taboo" behaviors and perceptions that those behaviors are harmful (Gutierrez \& Giner-Sorolla, 2007). The same conclusion is also supported by a number of correlational studies (Horvath \& GinerSorolla, 2007; Haidt \& Hersh, 2001). The point of contact that the cultural cognition thesis, if demonstrated, would establish between cultural theory and these other works in morally motivated cognition would also lend strength to the psychological foundation of the former's account of the origins of risk perceptions. 


\section{Research Hypotheses}

We conducted a study to assess how cultural values influence the perceptions of the risks and benefits of the HPV vaccine. The study had two objectives. One was to explore sources of the contemporary debate over mandatory school vaccination. The other was to assess the cultural cognition thesis by experimentally testing specific mechanisms through which culture might be thought to influence risk perceptions. We looked at two such mechanisms: biased assimilation and polarization and the credibility heuristic.

\section{Biased Assimilation and Polarization}

Biased assimilation refers to the tendency of individuals selectively to credit and dismiss information in a manner that confirms their prior beliefs. As a result, persons of opposing predispositions, it is thought, become more divided, not less, as they react to balanced arguments (Lord, Ross \& Lepper, 1979). ${ }^{3}$

The cultural cognition thesis implies that this dynamic will interact with culture. That is, people will selectively credit or discredit information on risk in a manner that fits their cultural predispositions toward them, and thus polarize along cultural lines (Kahan, Braman, Slovic, Gastil \& Cohen, 2009).

The cultural theory of risk features a typology proposed by Mary Douglas (1970). That typology classifies worldviews, or preferences for how society should be organized, along two dimensions, which Douglas called "group" and "grid." A "high group" worldview supports a relatively communitarian society, in which the needs of the collective take precedence over those of the individual and in which the collective is deemed responsible for securing the conditions of individual flourishing. A "low group" worldview, in contrast, supports an individualistic society, in which individuals are expected to secure the conditions of their own well-being without 
interference or assistance from the collective. A "high grid" worldview supports a hierarchical social order, in which all manner of prerogatives and obligations are assigned in a stratified way on the basis of relatively stable individual characteristics, such as gender, ethnicity, and class. A "low grid" worldview supports an egalitarian social order in which such characteristics are treated as irrelevant to the distribution of status and entitlements. "Group" and "grid" define cross-cutting continua, making it possible for groups to subscribe to outlooks that combine elements of either hierarchy or egalitarianism with elements of either communitarianism or individualism (Rayner, 1992).

We hypothesized that cultural worldviews so defined would generate competing predispositions toward the risks and benefits of mandatory HPV vaccination. Hierarchy and individualism, we predicted, would dispose individuals to see relatively more risk, the former because mandatory vaccination of school girls seems to condone sexual behavior that defies traditional gender norms, and the latter because mandatory vaccination intrudes on individual decision-making. Accordingly, we expected persons who held these worldviews (particularly in combination) to perceive greater risks and smaller benefits in HPV vaccination. In contrast, we surmised that individuals who held egalitarian and communitarian worldviews (particularly in combination) would see greater benefits and fewer risks, precisely because such a program seems to express tolerance for behavior that denigrates traditional, patriarchal norms and embodies collective commitment to the provision of a good essential to individual well-being.

The predicted relationship between biased assimilation and culture implies that these predispositions should influence how individuals react to information. Accordingly, the riskperception gulf between relatively hierarchical and individualistic persons, on the one hand, and 
relatively egalitarian and communitarian ones, on the other, should grow when such persons are exposed to arguments about the risks and benefits of mandatory vaccination.

\section{Credibility Heuristic}

It has been known for decades that individuals' evaluations of the strength of an argument depends largely on how credible they find the source of that argument (Hovland \& Weiss, 1951-52). Elements of credibility include knowledge, honesty and impartiality (e.g. McCroskey \& Young, 1981; Pornpitakpan, 2004). It is also well established that individuals tend to impute these qualities to, and hence to be more persuaded by, information sources with whom they have some "in group" connection, and to deny the same to "out group" information sources (Mackie \& Quellar, 2000; Clark \& Maass, 1988, p. 381).

The cultural cognition thesis suggests that the operation of the credibility heuristic will be highly sensitive to the source's and target's cultural worldviews. On this account, cultural affinity and cultural difference supply the relevant in-group/out-groups references that in turn determine whom people see as knowledgeable, honest, and unbiased, and thus worthy of being credited in debates about risk. Accordingly, we hypothesized that the effect of HPV-vaccine arguments in polarizing persons of diverse values would be either accentuated or muted depending on their relative affinity with the cultural values of argument sources taking one position or the other on the risks and benefits of mandatory vaccination.

\section{Methods}

\section{Overview}

We constructed a multi-part experiment to test these hypotheses. It involved a betweensubjects design in which perceptions of HPV vaccine risks and benefits were measured in three conditions: "no argument," in which subjects furnished their responses without being exposed to 
any arguments about mandatory vaccination programs; "unattributed arguments," in which subjects furnished responses after being exposed to opposing arguments unattributed to identified sources; and "culturally identifiable advocates," in which subjects furnished responses after being exposed to opposing arguments attributed to fictional policy experts designed to be perceived as possessing one or another of the combination of worldviews featured in cultural theory. Our biased-assimilation hypotheses implied that the gap between relatively egalitarian and communitarian subjects, on the one hand, and relatively hierarchical and individualistic ones on the other, would be larger in the "unattributed arguments" than in the "no arguments" condition. Our credibility-heuristic hypotheses implied that the size of this gap would vary in the "culturally identifiable advocate" condition depending on the relative affinity between subjects' values, on the one hand, and those of the advocates presenting the opposing arguments, on the other.

\section{Sample}

Experiment subjects consisted of a demographically diverse, national sample of 1,538 U.S. adults. They were drawn randomly from a panel of approximately 40,000 individuals recruited by Knowledge Networks for participation in scholarly public opinion analysis. ${ }^{4}$ Subjects were tested in two separate waves of on-line experiments (first the "no argument" and "unattributed arguments" conditions, then the "culturally identifiable advocates" condition) administered by Knowledge Networks in April and August of 2007. The sample size was 254 for the no-argument condition, 252 for the argument-without-advocate condition, and 1,032 for the argument-with-advocates condition.

\section{Measures}


Cultural worldview. The subjects' cultural worldviews were measured (in a prescreening conducted in advance of the experiment) with two scales used in previous studies of the cultural theory of risk and cultural cognition (Kahan, Braman, Slovic, Gastil \& Cohen, 2009; Kahan, Braman, Monahan, Callahan \& Peters, in press; Kahan, Braman, Gastil, Slovic \& Mertz, 2007; Kahan \& Braman, 2008; Kahan, Hoffman \& Braman, 2009). "Hierarchy-Egalitarianism" ("Hierarchy") consisted of 12 items, and "Individualism-Communitarianism" ("Individualism") 18 items, designed to assess subjects' worldviews along those two dimensions. Items consisted of statements (e.g., "A lot of problems in our society today come from the decline in the traditional family, where the man works and the woman stays home"; "Society works best when it lets individuals take responsibility for their own lives without telling them what to do"), to which respondents indicated their level of disagreement or agreement on a four-point scale. Both Hierarchy $(\alpha=.80)$ and Individualism $(\alpha=.82)$ were highly reliable. ${ }^{5}$

HPV risk-benefit perception and introductory statements. Subjects in all conditions responded on a four-point scale to a series of items (randomly ordered) relating to HPV vaccine risks and benefits.

POLICYNEED. It is important to devise public health policies to reduce the spread of HPV. [Strongly disagree, disagree, agree, strongly agree]

HPVSAFE. The HPV vaccine is safe for use among young girls. [Strongly disagree, disagree, agree, strongly agree]

VACDANGER. Universal vaccination of girls for HPV will likely endanger their health. [Strongly disagree, disagree, agree, strongly agree] HPVACTIVE. Universal vaccination of girls for HPV will lead girls to become more sexually active. [Strongly disagree, disagree, agree, strongly agree] 
FALSESECURITY. Girls vaccinated against HPV are more likely to engage in sex without a condom. [Strongly disagree, disagree, agree, strongly agree] HPVBENEFIT. How beneficial would you say universal vaccination of girls against HPV is likely to be? [Not at all beneficial, slightly beneficial, moderately beneficial, very beneficial]

HPVRISK. How risk would you say universal vaccination of girls against HPV is likely to be? [Not at all risky, slightly risk, moderately risky, very risky]

The items were combined into a scale, VACRISK $(\alpha=.84)$, in which POLICYNEED, HPVSAFE, and HPVBENEFIT were reverse-coded, that measured a latent disposition to see risk over benefit.

Before responding to these items, subjects read an introductory statement. In all conditions, that statement began,

Some public health experts favor universal vaccination of American girls (at or before age 12) to protect them from catching human papillomavirus (HPV). Other public health experts oppose such a program.

The "no argument" condition subjects were then advised "[w]e'd like to know what you think" and immediately requested to respond to the risk-benefit items.

Pro and con arguments. Before they responded to the risk-benefit items, the 250 subjects in the "unattributed arguments" condition were directed to read opposing, pro- and conarguments (juxtaposed on the screen, and rotated in position), which were introduced with the statement "[h]ere are what two opposing policy experts say." The arguments are presented in Figure 1. 


\section{Figure 1. Opposing arguments on mandatory HPV vaccination}

For HPV vaccination program. Studies show that nearly $50 \%$ of sexually active Americans now contract HPV, which is the leading cause of cervical cancer. Girls administered the vaccine will be protected from a variety of forms of HPV, which account for $70 \%$ of the cancers attributed to the virus. It is critical for vaccinations to be administered before the age at which girls are likely to become sexually active, because once they are exposed to HPV through sexual activity the vaccine won't be effective. The Food and Drug Administration has certified the vaccine as safe for use. Because so few girls even know what HPV is, it is illogical to suggest that the vaccination will cause them to become more sexually active or to engage in unsafe sex. It is therefore clear that universal vaccination of girls against HPV will make a major positive contribution to public health in America.
Against HPV vaccination program. The rate of cervical cancer, a disease caused by HPV, is in fact extremely low: it accounts for less than $1 \%$ of all the cancer cases in the U.S. every year. Moreover, the vaccine offers no protection against types of HPV responsible for $30 \%$ of the cancers caused by the virus. Nevertheless, those who receive the vaccination are likely to assume it gives them complete protection. They are therefore more likely to engage in sexual activity, and to engage in sex without a condom, increasing their risk of contracting HPV and other sexually transmitted diseases, like HIVAIDS, and of becoming pregnant. Finally, the HPV vaccine might well turn out to have unanticipated and dangerous side effects just like many other medicines approved by the Food and Drug Administration. In sum, a universal HPV vaccine is likely to harm girls and women more than it helps.

Culturally identifiable advocates and cultural affinity scores. After the introductory statement, the 1,022 subjects in the "culturally identifiable advocate" condition read:

Here are what two opposing policy experts say. Each advocate is on the faculty of a major university and has written numerous books on public policy."

They were then shown the same pro- and con- arguments (again juxtaposed, and rotated) as had been shown to subjects in the "unattributed arguments" condition. However, at the top of each argument in the "culturally identifiable advocate" condition there appeared a picture of the ostensible source of the argument and a set of his (fictional) book titles (Figure 2). 


\section{Figure 2. Culturally Identifiable Advocates}



Egalitarian 
The advocates were created in a separate set of pretests. In the first set, pretest subjects were each shown a picture of one individual and asked to guess how that individual would respond to the cultural worldview items. In subsequent pretests, additional subjects were asked to guess the responses of a single pictured individual described as the author of a list of books. Over the course of several such tests, we created a set of four advocates, each of whom generated a highly reliable imputed culture score that was significantly different from each other one's and that located him in one of the four quadrants ("hierarchical individualist," "hierarchical communitarian," "egalitarian individualist," and "egalitarian communitarian") demarcated by the intersection of Douglas's (1970) two worldview dimensions. To avoid the entangling of culturalaffinity influences on credibility with any related to the source's race and gender, all the culturally identifiable advocates were white males. The pictured individuals consisted of three law school professors not known to the general public and one picture from a licensed royaltyfree photo disc.

In the credibility component of the actual experiment, arguments were randomly matched with advocates. Each of the four advocates could be assigned to either argument and be opposed to any one of the other three advocates. There were thus 12 distinct advocate-argument pairings in total. Each subject in the "culturally identifiable advocate" condition (none of whom participated in pretests used to construct the advocates) was randomly assigned one of these argument-advocate pairings. 
Figure 3. Derivation of "Cultural Affinity" Measure. The worldview scores of a subject and the worldview scores attributed to fictional policy experts can all be mapped on a grid constructed by the intersection of the four-point Hierarchy-Egalitarian and IndividualistCommunitarian worldview scales. The proximity of the subject's worldview to the pro-vaccine advocate's worldivew, $P A$, equals $\sqrt{ }\left(p^{2}+q^{2}\right)$. The proximity of the subject's worldview to the conadvocate's worldview, $C A$, equals $\sqrt{ }\left(r^{2}+s^{2}\right)$. A "Cultural Affinity" score can be derived by subtracting $C A$ from $P A$, which reflects how much closer the subject's worldview is to that of the con-advocate than to that of the pro-advocate. The cultural-credibility hypothesis predicts that Cultural Affinity will correlate positively with VACRISK after controlling for subjects' cultural worldviews.

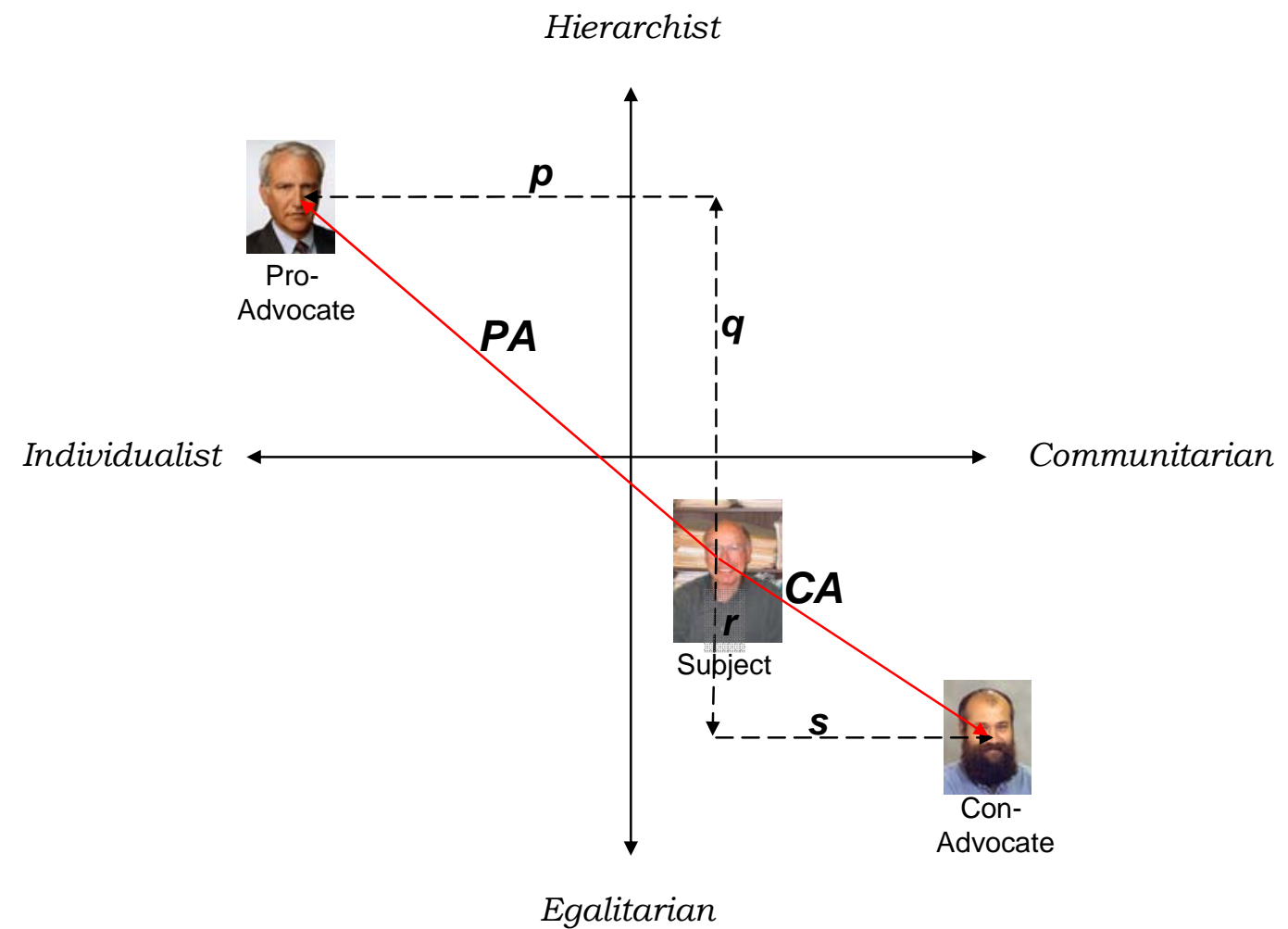

Treating the grid created by the intersection of the two worldview scales as a "cultural map," it was possible to compute the distance between every subject's worldview and the worldview imputed to each advocate in his or her pairing. Insofar as both Hierarchy and Individualism are continuous four-point scales, they can be conceived of as forming a $4 \mathrm{x} 4$ grid in which they intersect each other at right angles at their respective midpoints. On the resulting grid, each subject can be located at a unique two-point coordinate corresponding to his or her respective Hierarchy and Individualism scores. The "distance" between any subject and any 
advocate on that grid equals the square root of the sum of the squares of the differences between the Hierarchy scores of the subject and advocate and the Individualism scores of the subject and the advocate. Subtracting the distance between the subject's and the con-advocate's worldviews from the distance between the subject's and the pro-advocate's worldviews generated a "Cultural Affinity" score that measured how much more proximate the subject's values were to the con-

advocate's than to the pro-advocate's (Figure 3). The hypothesized relationship between cultural affinity and credibility implied that, holding subjects' cultural worldviews constant, subjects' VACRISK score (their perceived predominance of risk to benefits) would increase as their Cultural Affinity score (the relative proximity of their cultural values to the perceived values of the con-advocate) increased.

\section{Statistical Analyses}

It was anticipated that the results for both the biased-assimilation and credibility-heuristic components of the experiment would be analyzed by multivariate regression. Multivariate regression is preferred over analysis of variance (ANOVA) for experimental designs, such as ours, that involve measure of the effect of continuous predictors (Aiken, West \& Reno, 1991, pp. 167-68; Judd, 2000, p. 372; Jaccard \& Turrisi, 2003, p. 86). ${ }^{6}$ 


\section{Results}

\section{Biased Assimilation and Polarization}

In the first stage of the experiment, we compared the risk perceptions of subjects in the "no argument" condition and the "unattributed arguments" condition. This procedure permitted testing of the biased assimilation hypotheses.

Zero-order correlations were consistent with the hypothesized results. In the "no argument" condition, Hierarchy correlated positively $(r=.18, p<.01)$ with VACRISK, indicating that subjects perceived greater risk as they became more hierarchical and less risk as they became more egalitarian. Consistent with biased assimilation, this effect was even larger $(r$ $=.32, p<.01)$ in the "unattributed arguments" condition. The simple correlation between Individualism and VACRISK $(r=.07, p=.27)$ was not significant in the "no arguments" condition. However, also consistent with biased assimilation, there was a significant positive correlation $(r=.19, p<.01)$ in the "unattributed arguments" condition, indicating that subjects exposed to arguments became more concerned about risk as their worldviews became more individualistic and less concerned as their worldviews became more communitarian.

Multivariate analysis allowed for a more exacting assessment of the results. To confirm the significance of the experimental manipulation and to disentangle the relative contributions of the two worldview measures, we used a regression analysis in which the cultural worldview measures, assignment to the "unattributed arguments" (Argument $=1)$ or "no argument" condition (Argument $=0$ ), and finally the variables for the interactions between the experimental condition and each cultural worldview measure were entered in three steps (Cohen, Cohen, West \& Aiken, 2003, p. 555-56; Judd, 2000, pp. 374-75). 
The results, as shown in Table 1, confirmed that argument exposure generated a culturally polarizing effect. The significance of the $F$ statistic in step 2 , indicating that the addition of the argument exposure variable significantly increased the explanatory power of the model, shows that argument exposure affected subjects' responses overall. Neither the interaction between Hierarchy and argument exposure $(B=.29, p=.08)$ nor Individualism and argument exposure $(B=.19, p=.40)$ was statistically significant on its own. However, the combined effect of these interactions was significant: the significant $F$ statistic in step 3 indicates that taking account of the differential effect of argument exposure across persons of diverse cultural worldviews has an effect that is not captured by the impact of argument exposure alone (Judd, 2000, p. 373). Moreover, because the signs of both of the interaction variables are positive, it is clear that argument exposure significantly increases risk concern as subjects' worldviews become simultaneously more hierarchical and individualistic.

Table 1. Regression Analysis of results from "No Argument" and "Unattributed Arguments" Conditions

\begin{tabular}{lccc} 
& Step 1 & Step 2 & Step 3 \\
\hline Hierarchy & $\mathbf{0 . 3 8}$ & $\mathbf{0 . 4 1}$ & $\mathbf{0 . 2 7}$ \\
& $(0.09)$ & $(0.08)$ & $(0.12)$ \\
Individualism & 0.09 & -0.01 & -0.11 \\
& $(0.11)$ & $(0.11)$ & $(0.17)$ \\
Arguments & & $\mathbf{0 . 5 1}$ & -0.72 \\
& & $(0.07)$ & $(0.50)$ \\
Hierarchy x Arguments & & $\underline{0.29}$ \\
Individualism x Arguments & & & $(0.17)$ \\
& & & 0.19 \\
Constant & $\mathbf{1 . 3 7}$ & $\mathbf{1 . 3 3}$ & $(0.22)$ \\
& $(0.27)$ & $(0.25)$ & $\mathbf{1 . 9 6}$ \\
\hline$R^{2}$ & 0.07 & 0.16 & $0.37)$ \\
$F$ for $\Delta R^{2}$ & & $\mathbf{5 3 . 2 0}$ & $\mathbf{4 . 1 1}$ \\
\hline
\end{tabular}


$N=506$. Dependent variable is 4-pt, VACRISK scale. Coefficients are unstandardized regression weights, with standard errors in parentheses. Bold denotes significant at $p \leq .05$, underscored at $p$ $\leq .10$.

The practical impact of this effect can be illustrated by using the regression equation in step 3 to estimate scores on VACRISK. Setting the values for Hierarchy one standard below and one standard deviation above the mean on that scale generates the estimated responses for moderately "egalitarian" and "hierarchal" individuals, respectively (Cohen, Cohen, West \& Aiken, 2003, p. 558). Similarly, setting the values for Individualism one standard deviation below and above the mean of the range for sample scores on that scale generates the estimated response for moderately "communitarian" and moderately "individualistic" persons, respectively. By appropriately combining these values, it is possible to estimate the VACRISK scores, along with associated standard errors, for representative "hierarchical individualists," "hierarchical communitarians," "egalitarian individualists," and "egalitarian communitarians," both when they are exposed to arguments and when they are not.

The results of this analysis are displayed in Table 2 . As can be seen, being exposed to arguments raises the perception of risk overall. But how much it increases it is conditional on cultural worldviews. The difference on the four-point VACRISK scale between a hierarchical individualist and an egalitarian communitarian - the types of subjects we predicted would be most disposed to react in extreme ways to arguments - increases from .16 in the "no argument" condition to .57 in the "unattributed arguments" condition, or .41 overall, a statistically significant change. 
Table 2. Estimated Values (and Standard Errors) For Effect of Receiving Unattributed Arguments

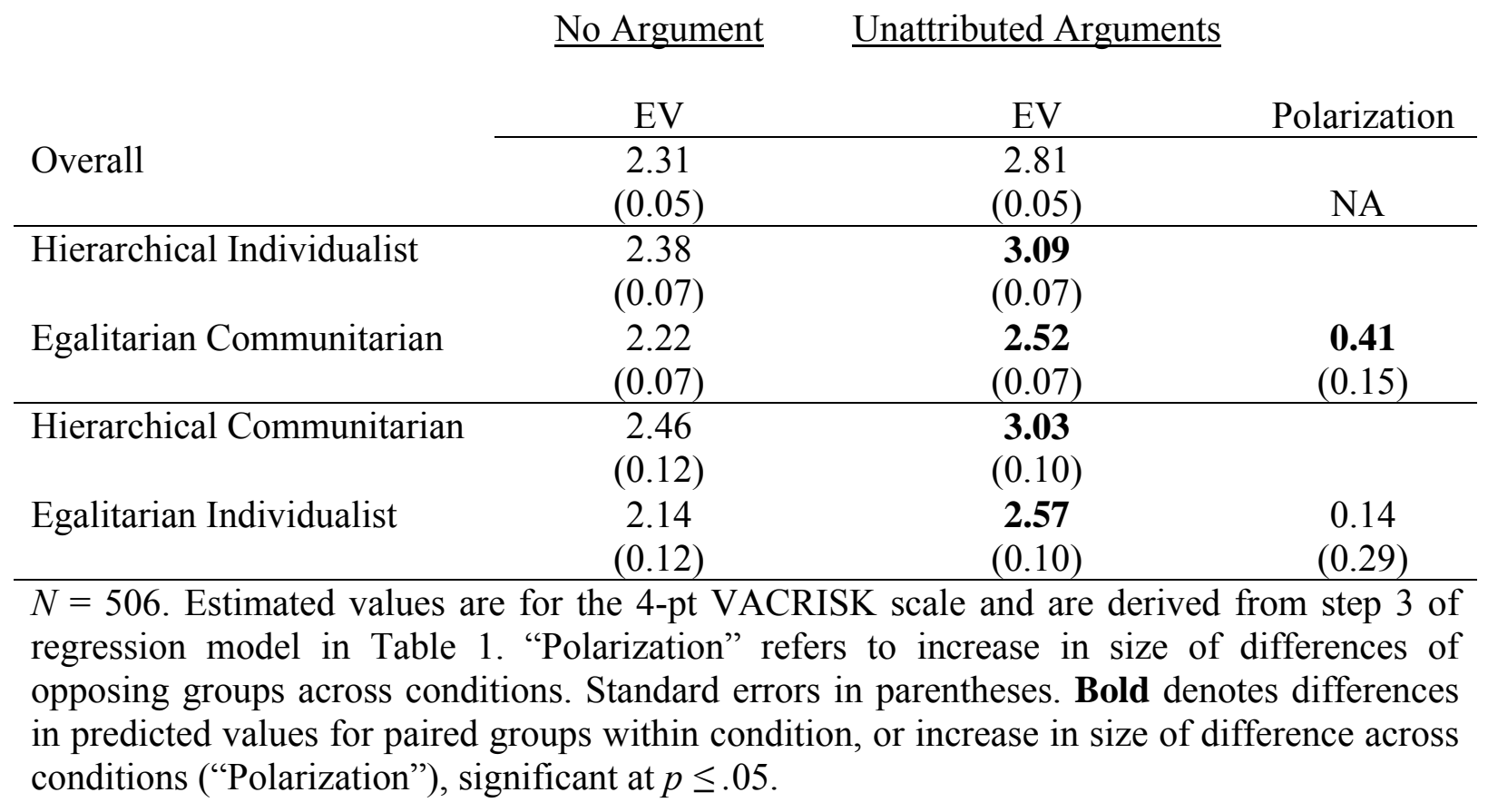

The difference between an egalitarian individualist and a hierarchical communitarian increases across conditions, too, but by a lesser and not statistically significant amount. This result confirms that the significance of the interaction between argument exposure and the culture variables reflected in Step 3 of the regression model arises from sum of the differential effects of arguments across both dimensions of worldview as opposed to the differential effect of arguments across only one of them.

\section{Credibility Heuristic}

We also used multivariate regression to analyze the results in the credibility experiment. In the analysis, subject scores on VACRISK, the composite mandatory-vaccine risk-perception scale, were regressed on subjects' cultural worldview scores and on their "cultural affinity" scores, which measured how much more proximate their cultural worldviews were to the advocate presenting the con-vaccination argument than the pro-vaccination argument (Figure 3). 
The results are reflected in Table 3. The coefficient for Cultural Affinity was positive and statistically significant: As hypothesized, the closer subjects' values were to the con-argument advocate's than to the pro-advocate's, the more risk subjects were disposed to see. The positive coefficients for Hierarchy and Individualism indicated that, holding proximity to pro- and conadvocates constant, subjects were more disposed to see risk as their values became more hierarchical and individualistic. This effect was only marginally significant $(p=.09)$, however, for Individualism considered alone.

Table. 3. Regression Analysis of Results in "Culturally Identifiable Advocates” Condition

Hierarch

Individ

Cultural Affinity

Constant
0.42

$\underline{0.14}$

0.19

1.43

$(0.22)$

$N=1,032$. Dependent variable is 4-pt, VACRISK scale. "Cultural affinity" measures how much closer subject's values were to values of advocate opposed to vaccine than to advocate supporting vaccine. Coefficients are unstandardized regression weights, with standard errors in parentheses. Bold denotes significant at $p \leq .05$, underscored at $p \leq .10$.

To illustrate the practical impact of advocate-subject cultural affinity, one can use the regression analysis in Table 3 to estimate VACRISK scores for appropriately specified independent variable values. Combinations of Hierarchy and Individualism values set one standard deviation either above or below the means on those scales can again be used to assess the responses of representative "hierarchical individualists," "egalitarian communitarians," "hierarchical communitarians," and "egalitarian individualists."

The value assigned to Cultural Affinity can then be adjusted to see how subjects of those types react to advocates of those or opposing types. Specifying a cultural affinity value at its 
maximum value, for example, predicts how subjects respond in a case in which the con-argument is made by an advocate whose cultural values are maximally close to their own —effectively one in her own "quadrant" of the group-grid culture map; and the pro-argument by an advocate whose cultural values are maximally remote from their own - necessarily one in the quadrant diagonal to the subject's own. Specifying a cultural affinity value at its minimum value, in contrast, would predict how subjects would respond were the pro-argument made by an advocate whose values are maximally close to their own and the con-argument by an advocate whose values are maximally remote from theirs. Finally, setting the Cultural Affinity variable at zero predicts how subjects would respond when both advocates had values equally proximate (including either maximally close or maximally remote) from theirs.

Table 4 presents estimates under various alignments of advocates and arguments. In the "expected alignment" scenario, the Cultural Affinity value is set at its maximum for hierarchical individualists and at its minimum for egalitarian communitarians. The resulting values simulate how such subjects would respond were the pro-argument made by the egalitarian communitarian advocate and the con-argument made by the hierarchical individualist (see Figure 2). The difference in resulting risk perceptions is large and statistically significant. In the "unexpected alignment" scenario, the Cultural Affinity value is set at its minimum for hierarchical individualists and at its maximum for egalitarian communitarians. The resulting values then represent how such subjects would respond were the con-argument made by the egalitarian communitarian advocate and the pro-argument made by the hierarchical individualist. The difference in the estimated values now is extremely small and not statistically significant. This result is consistent with the credibility-heuristic hypothesis that the cultural identity of advocates can accentuate or mitigate polarization in risk perceptions of culturally diverse subjects. 
Table 4. Expected Values for Risk Perceptions by Cultural Worldview in "Culturally Identifiable Advocate Condition

Advocate-Argument Alignment

\begin{tabular}{lccccc} 
& Expected & \multicolumn{2}{c}{ Unexpected } & Intramural & \\
\cline { 2 - 6 } & EV & EV & Depolar. & EV & Depolar. \\
\hline Hierarchical Individualist & $\mathbf{3 . 2 7}$ & 2.93 & & $\mathbf{3 . 1 0}$ & \\
& $(0.08)$ & $(0.08)$ & & $(0.04)$ & \\
Egalitarian Communitarian & $\mathbf{2 . 4 4}$ & 2.77 & $\mathbf{- 0 . 6 7}$ & $\mathbf{2 . 6 0}$ & $\mathbf{- 0 . 3 3}$ \\
& $(0.08)$ & $(0.08)$ & $(0.24)$ & $(0.04)$ & $(0.12)$ \\
\hline Hierarchical Communitarian & $\mathbf{3 . 1 6}$ & 2.83 & & 3.00 & \\
& $(0.08)$ & $(0.08)$ & & $(0.06)$ & \\
Egalitarian Individualist & $\mathbf{2 . 5 4}$ & 2.87 & $\mathbf{- 0 . 5 8}$ & 2.71 & $\mathbf{- 0 . 3 3}$ \\
& $(0.08)$ & $(0.08)$ & $(0.24)$ & $(0.06)$ & $(0.12)$ \\
\hline
\end{tabular}

$N=1,032$. Estimated values derived from regression model for 4-pt VACRISK scale in Table "Depolar." indicates decrease in size of the difference between paired groups in the specified advocate-argument alignment compared to the difference between those groups in the "expected alignment." Standard errors in parentheses. Bold denotes difference between paired groups, or decrease in size of difference relative to "expected alignment" ("Depolar."), significant at $p \leq .05$.

The hypothesis is also consistent with the result generated in a so-called "intramural

alignment" scenario. There the Cultural Affinity value is set at zero. The estimated VACRISK

values are now consistent with those that result when subjects react to arguments made by advocates whose values are equally proximate to theirs — as they would be, for example, if subjects of a particular combination of worldviews received information from advocates who both shared or rejected her outlooks. A significant difference persists between the risk perceptions of hierarchical individualists and those of egalitarian communitarians (as one would expect based on the significant coefficient for Hierarchy and marginally significant coefficient for Individualism, respectively, in the regression analysis), but the size of the difference is significantly smaller than it is in the "expected alignment" scenario.

Similar results are observed for Hierarchical Communitarians and Egalitarian Individualists. If subjects of these types observe advocates who share their values advancing the arguments that fit the subjects' respective predispositions (pro- for Egalitarian Individualists and 
con- for Hierarchical Communitarians), and observe advocates who reject their values advancing arguments that conflict with subjects' predispositions, the estimated gulf between subjects with these values widens. The estimated gap shrinks, in contrast, if the argument-advocate alignment is reversed, as it does if subjects of these types observe advocates whose values are equally proximate or remote from their own on both sides of the debate.

\section{Analytic Summary}

The results of both stages of the experiment are summarized in Figure 4. As expected, hierarchy and individualism, particularly when combined, disposed subjects to be more concerned, egalitarianism and communitarianism to be less, about the risks of HPV vaccination. Those dispositions exerted a relatively modest effect in the absence of arguments about the risks and benefits of the vaccine. Consistent with biased assimilation and polarization, however, the size of the disagreement between subjects with those values grew when they were exposed to balanced arguments.

Consistent with the credibility heuristic hypotheses, moreover, the polarizing effect of information was highly sensitive to the cultural identity of the advocates making pro- and conarguments. The results of this part of the experiment suggest that polarization grows where culturally diverse subjects see the argument they are disposed to accept being made by the advocate whose values they share, and the argument they are predisposed to reject being made by the advocate whose values they repudiate. In contrast, when subjects see the argument they are disposed to reject being made by the advocate whose values they share, and the argument they are predisposed to accept being made by the advocate whose values they repudiate, polarization shrinks to the point of disappearing. When subjects see the arguments being made 
by advocates whose values are equally congenial (or uncongenial) to theirs, polarization is

modest.

Figure 4. Risk Perceptions By Culture Type Across Conditions. Scores on 4-point VACRISK scale under experimental conditions specified in Tables 2 and 4. Confidence intervals reflect 0.95 level of confidence.



\section{Discussion}

The central hypotheses of the study were largely vindicated. The results of the experiment suggest that disagreements about the risks and benefits of HPV vaccination are shaped by cultural values, which exert their influence through the biased assimilation of 
information and through attributions of information-source credibility. We now consider some of the implications of these findings.

\section{Advancing the Cultural Theory of Risk}

Most of the work to date in cultural theory has been correlational in nature. Large-sample surveys furnish support for cultural theory because they reveal that risk perceptions are distributed across persons in patterns that can be cogently explained only if individuals' values are exerting an influence — one independent of myriad other factors associated with variance in risk perception — on individuals' beliefs about societal dangers and how they should be abated (see Kahan et al., 2007, p. 473). Nevertheless, this mode of proof is necessarily indirect. Correlations suggest causation but don't prove it, in this setting primarily because they don't permit observation of the psychological mechanisms through which cultural values influence risk perceptions.

Continued advancement of cultural theory thus depends on experimental investigations designed to furnish direct evidence of such mechanisms. By documenting the role played by two mechanisms — biased assimilation and the credibility heuristic — our study helps to corroborate and extend cultural theory.

\section{Advancing Enlightened Public Deliberation on Risk Regulation}

The results of our study also have practical implications for the role of public deliberations in risk regulation. Indeed, the mechanisms of cultural cognition we have identified suggest an approach to public risk communication that is quite different from conventional strategies.

The scholarly study of risk regulation is dominated by two theories, which support opposing philosophies of risk communication. The "rational weigher" position asserts that 
individuals, in aggregate and over time, tend to process information about risk in a manner that promotes their expected utility (Starr, 1969; Viscusi, 1983; Philipson \& Posner, 1993). This theory implies that the best way to promote sensible democratic decisionmaking about risk is simply to disseminate sound scientific information as widely as possible.

The "irrational-weigher" theory, in contrast, holds that individuals, due to various cognitive limitations and biases, are incapable of processing risk information in a manner that promotes their expected utility (Margolis, 1996; Sunstein, 2005). This position counsels transferring as much risk regulatory power as possible to politically insulated experts, whose specialized training permits them to evaluate information more dispassionately and systematically (Breyer, 1993; Sunstein, 2005). Risk communication, on this view, is simply a bad idea; because the public is inherently predisposed to react irrationally, the dissemination of even scientifically sound information is likely to trigger inordinate states of alarm, which in turn provoke ill-considered regulatory responses from democratically accountable political institutions (Kuran \& Sunstein, 1998). Accordingly, when governmental and other experts are confronted with public concerns over particular risks, "the best approach may well be this: Change the subject.... [D]iscuss something else and to let time do the rest" (Sunstein, 2005, p. 125).

At first glance, the mechanisms of cultural cognition can be seen as amplifying the irrational-weigher theory's skepticism about the efficacy of risk communication (Sunstein, 2006). Corroborating earlier findings (Kahan, Braman, Slovic, Gastil, \& Cohen, 2009), our study found that individuals are motivated selectively to credit empirical claims in a manner that coheres with their visions of the ideal society. When they see advocates debating such a risk, individuals, we found, are motivated to defer to the ones who they perceive to share their basic 
view of how society should be organized. Because the same forces that motivate individuals generally to adopt positions congenial to their cultural outlooks are likely to induce policy advocates to do so, a deliberative climate is likely to emerge in which culturally diverse members of the public consistently see advocates they identify with presenting arguments they are already predisposed to accept, and advocates they do not identify with presenting arguments they are predisposed to reject. The self-reinforcing effects of culturally biased assimilation and cultural credibility thus make the prospect for spontaneous convergence on sound scientific information exceedingly remote.

Nevertheless, the cultural cognition account of why risk communication can easily fail is more complicated than the irrational-weigher theory's, and ultimately less despairing of the prospects for informed democratic deliberation. The irrational weigher theory attributes discrepancies between expert and public risk perceptions solely to the public's reliance on "error prone" heuristic or "system 1" forms of reasoning (Sunstein, 2005; Kahneman, 2003). But the cultural cognition of risk shows that the interaction of heuristic reasoning with individual values must be taken into account as well in order to explain how exposure to the common information can generate pronounced individual differences among persons of diverse outlooks and related characteristics. If making public deliberations responsive to the guidance of sound scientific evidence depends on endowing members of the public with the capacity to evaluate scientific evidence through use solely of systematic or "system 2" forms of reasoning, then irrationalweigher theorists are clearly right to believe that sound risk regulation is not compatible with genuinely participatory modes of lawmaking. But if the antagonism between heuristic reasoning and recognition of sound scientific evidence is attributable in larger part to the polarizing influence of cultural cognition, then risk communication strategies aimed at neutralizing or 
mitigating cultural cognition might make the objective of enlightened public deliberations over risk much more realistic (Kahan, 2008).

The results of our study suggest the possibility of such strategies. As evidenced in the biased assimilation experiment, hierarchical individualists were disposed to see the HPV vaccine as risky, the egalitarian communitarians to see it as safe. But if subjects of those types observed advocates of their respective persuasions arguing for and against mandatory vaccination, respectively, egalitarian communitarians saw significantly more risk and hierarchical individualists significantly less. As a result, in this "unexpected alignment" scenario, the views of such subjects approached convergence, presumably because they were then deriving comparable informational content from the arguments for and against mandatory vaccination. It might be inferred, then, that one technique for eliminating cultural polarization is to arrange for members of the public to be exposed to debates in which advocates of diverse cultural identities present positions contrary to the predispositions of those who share their values.

But this strategy for mitigating cultural conflict on risk strikes us as unrealistic and likely self-defeating. The proposal to orchestrate counter-intuitive pairings of arguments and advocates not only assumes an unrealistic degree of control over who says what —or is perceived to be saying what—in public debate. It also ignores a very real risk that such orchestration will backfire. Ordinary citizens are of course aware that they must rely on trustworthy sources to identify which contested empirical claims are worthy of belief; they are thus aware that parties with an interest in the acceptance of one or another claim have an incentive to manipulate public perceptions of the position that trusted authority figures hold. As a result, if they suspect manipulation, members of the public (quite sensibly) are likely to take it as corroboration that the 
position they were predisposed to reject is in fact the weaker one-a dynamic Lessig (1995) calls the "Orwell effect."

Indeed, something very much like this appears to have occurred already in the debate over mandatory HPV vaccination. In 2007, Texas became the first state with a mandatory school vaccination program when its Governor, Rick Perry, issued an executive order creating one. Because Perry is a conservative, southern Republican, his action was viewed as signaling potential abatement of the ideological opposition that had been halting adoption of HPV programs in other states (Blumenthal, 2007). It was revealed shortly thereafter, however, that Merck \& Co., the manufacturer of what was then the only approved vaccine, had been a contributor to Perry's re-election campaign in 2006. In the resulting uproar, the state legislature passed a law overturning the Governor's order, and Perry backed off his pledge to veto that legislation (Elliot, 2007).

A likely more effective (and morally more defensible) strategy for counteracting the influence of cultural cognition in debates over the HPV vaccine is to promote a genuinely pluralistic argument environment. The results in the "intramural alignment" scenario of our study - in which we measured the impact on subjects when arguments were assigned to advocates whose values were equally proximate to the subjects—also significantly reduced polarization. This finding suggests that the impact of cultural cognition would be relatively small if citizens observed persons of diverse values on both sides of the mandatory vaccination debate. Achieving a deliberative environment of that sort would certainly be more feasible than creating one in which advocate of various cultural identities consistently advanced positions contrary to what one would expect from individuals with their values. Indeed, achieving a pluralisticargument environment of this sort would seem to be especially practicable in structured 
deliberations (Fishkin, 1991, 1995; Gastil, 2008), where its presence or absence might help to explain the uneven patterns of success observed in the literature on this device (Ackerman \& Fishkin, 2004; Gastil, Black, and Moscovitz, 2008; Schkade, Sunstein \& Hastie, 2007).

Even more important, it seems plausible to believe that efforts to create such an environment—in structured deliberative contexts or in public discussion generally—could be promoted transparently without risk of Lessig's "Orwell effect." Those engaged in seeking out and encouraging advocates of diverse persuasions who genuinely believe in their positions to participate on both sides of the debate can honest and credibly claim that their goal is not to manipulate the public to accept one position; rather it is to enable members of the public to decide for themselves what position to adopt in a climate calculated to permit them to consider the evidence free of a type of cognitive distortion persons of cultural persuasions resent.

Of course, one cannot be certain that such a strategy would work based solely on a study like the one we conducted. But for the practical-minded public advocate in need of immediate guidance, our results suggest that this approach might at least be worth a try.

\section{Future Research}

Speculations of this sort highlight the likely utility of follow-up studies. Such studies could be used both to refine practical strategies for managing the influence of cultural cognition on public deliberations and to extending the investigation of the dynamics of cultural cognition initiated in this study.

Indeed, the nature of the interaction of cultural values and the credibility heuristic would itself benefit from further examination. Our study suggests that cultural affinity influences source credibility but does not indicate exactly how or why. Credibility has been shown to rest on certain predicates, including the perceived knowledge and honesty and the likeability of the 
source (Lupia, 2002). One hypothesis worthy of testing, then, is whether these attributes are influenced by affinity between the perceived cultural values of the source and those evaluating his or her credibility.

An additional subject for investigation is whether the interaction between culture and credibility observed in this study extends to recognizable sources of risk communication. Trust of government regulators is an important predictor of risk concern (Slovic, Flynn \& Layman, 1991). Survey research shows that perceived value-affinity is an element of such trust (Siegrist, Cvetkovich \& Roth, 2000). Possible topics for study, then, include whether the variances in the level of trust that individuals have in agencies such as the FDA and the EPA is influenced by the affinity between subjects' cultural values and those they impute to officials in those agencies, and, if so, whether trust can be increased through strategies that enhance perceived cultural affinity with such officials.

Finally, and most importantly, the current study should be extended by examinations of potential mechanisms of cultural cognition. Interactions with the availability heuristic, with affect, with the status quo bias, and with identity-threat all are plausible sources of the impact of culture on risk perceptions (Kahan et al., 2007). Cultural cognition also likely interacts with the forms of social influence emphasized by the social amplification literature (Kasperson \& Kasperson, 1996; Pidgeon, Kasperson \& Slovic, 2003), explaining how such influences not only magnify risk perceptions but also likely magnify individual differences in perceptions, resulting in persistent states of polarization. 


\section{Conclusion}

The cultural theory of risk offers a distinctive, and distinctively provocative, account of political conflict over risk. On this account, individuals instinctively perceive behavior they abhor to be harmful and behavior they revere as benign (Douglas, 1966). As a result, even when citizens share a commitment to tolerating ways of life that differ from their own, they are likely to divide into bitter cultural factions as they deliberate over policies to mitigate damage to the environment, repel external threats, and promote public health (Douglas \& Wildavsky, 1982).

This paper described a study that used disagreement over mandatory HPV vaccination to test the cultural theory of risk. That study found that cultural values do indeed seem to generate divergent perceptions of the risk and benefits of the HPV vaccine. They exert this influence, study results suggest, through two related mechanisms - biased assimilation and the credibility heuristic.

We have discussed what we see as the principal theoretical and practical implications of these findings. But by far the most important implication of the study is the likely profit of additional studies of the mechanisms of cultural cognition. By identifying the heuristic processes through values influence perceptions of harm and danger, properly designed experiments have the potential to advance not only our understanding of the cultural theory of risk but also our ability to use that theory and related ones to promote enlightened public deliberation on risk regulation. 


\section{References}

Ackerman, B. A., \& Fishkin, J. S. (2004). Deliberation day. New Haven: Yale University Press. Alliance for Human Research Protection (2007, Feb. 8). More re: Merck's “help pay for vioxx" mandatory vaccine campaign. http://www.ahrp.org/cms/content/view/463/29/.

Blumenthal, R. (2007, Feb. 2). Texas is first to require cancer shots for schoolgirls, New York Times. Retrieved from http://www.nytimes.com/2007/02/03/us/03texas.html.

Breyer, S. G. (1993). Breaking the vicious circle: Toward effective risk regulation. Cambridge, Mass.: Harvard University Press.

Brody, J. E. (2007, May 15). HPV vaccine: Few risks, many benefits. New York Times. Retrieved from http://www.nytimes.com/2007/05/15/health/15brod.html.

Carreyrou, J. (2006, Apr. 16). Viral marketing: Questions on efficacy cloud a cancer vaccine. Wall Street Journal, p. 1.

Centers for Disease Control and Prevention, Office of Enterprise Communications. (2006, June 29). CDC's advisory committee recommends human papillomavirus virus vaccination. http://www.cdc.gov/od/oc/media/pressrel/r060629.htm.).

Clark, R. D., \& Maass, A. (1988). The role of social categorization and perceived source credibility in minority influence. European Journal of Social Psychology, 18(5), 381-394.

Cohen, J., Cohen, P., West, S. G., \& Aiken, L. S. (2003). Applied multiple regression/correlation analysis for the behavioral sciences (3rd ed.). Mahwah, N.J.: L. Erlbaum Associates.

Dake, K. (1991). Orienting dispositions in the perception of risk - an analysis of contemporary worldviews and cultural biases. Journal of Cross-Cultural Psychology, 22(1), 61-82.

DiMaggio, P. (1997). Culture and cognition. Annual Review of Sociology, 23, 263-287. 
Douglas, M. (1966). Purity and danger; an analysis of concepts of pollution and taboo. New York,: Praeger.

Douglas, M. (1970). Natural symbols: Explorations in cosmology. London,: Barrie \& Rockliff : Cresset Press.

Douglas, M., \& Wildavsky, A. B. (1982). Risk and culture : An essay on the selection of technical and environmental dangers. Berkeley: University of California Press.

Dunne, E. F., Unger, E. R., Sternberg, M., McQuillan, G., Swan, D. C., Patel, S. S., et al. (2007). Prevalence of HPV infection among females in the United States. JAMA, 297(8), 813-19.

Elliot, J. (2007, Mar. 9). Perry won’t veto bill blocking HPV order, Houston Chronicle. Retrieved from: http://www.chron.com/disp/story.mpl/metropolitan/4785851.html.

Ellis, R. J., \& Thompson, F. (1997). Culture and the environment in the pacific northwest. American Political Science Review, 91(4), 885-898.

Fishkin, J. S. (1991). Democracy and deliberation: New directions for democratic reform. New Haven: Yale University Press.

Fishkin, J. S. (1995). The voice of the people: Public opinion and democracy. New Haven: Yale University Press.

Focus on the Family (2007). Focus on the family's position statement: human papillomavirus vaccines. Retrieved from http://www.family.org/sharedassets/correspondence/pdfs/PublicPolicy/Position_StatementHuman Papillomavirus Vaccine.pdf.

Gastil, J. (2008). Political communication and deliberation. Los Angeles: SAGE Publications.

Gastil, J., Black, L., \& Moscovitz, K. (2008). Ideology, attitude change, and deliberation in small face-to-face groups. Political Communication, 25, 23-36. 
Gelman, A., \& Hill, J. (2007). Data analysis using regression and Multilevel/Hierarchical models. Cambridge ; New York: Cambridge University Press.

Gerber, A., \& Green, D. (1999). Misperceptions about perceptual bias. Annual Review of Political Science, 2, 189-210.

Gibbs, N. (2006, June 21). Defusing the war over the "promiscuity vaccine". Time. Accessed online April 9, 2009, http://www.time.com/time/nation/article/0,8599,1206813,00.html.

Gutierrez, R., \& Giner-Sorolla, R. (2007). Anger, disgust, and presumption of harm as reactions to taboo-breaking behaviors. Emotion, 7(4), 853-868.

Haidt, J., \& Hersh, M. A. (2001). Sexual morality: The cultures and emotions of conservatives and liberals. Journal of Applied Social Psychology, 31(1), 191-221.

Harris, G. (2006, June 9). U.S. approves use of vaccine for cervical cancer. New York Times, p. A1.

Horvath, M. A. H., \& Giner-Sorolla, R. (2007). Below the age of consent: Influences on moral and legal judgments of adult-adolescent sexual relationships. Journal of Applied Social Psychology, 37(12), 2980-3009.

Hovland, C. I., \& Weiss, W. (1951-52). The influence of source credibility on communication effectiveness. Public Opinion Quarterly, 15(4), 635-50.

Jaccard, J., \& Turrisi, R. (2003). Interaction effects in multiple regression (2nd ed.). Thousand Oaks, Calif.: Sage Publications.

Jenkins-Smith, H. (2001). Modeling stigma: An empirical analysis of nuclear waste images of Nevada. In J. Flynn, P. Slovic \& H. Kunreuther (Eds.), Risk, media, and stigma: Understanding public challenges to modern science and technology (pp. 107-32). London; Sterling, VA: Earthscan. 
Kahan, D. \& Braman, D. (2008). The Self-defensive Cognition of Self-defense, American Criminal Law Review. 45(1), 1-65.

Kahan, D. M. (2008). Two conceptions of emotion in risk regulation. Univ. Pa. L. Rev., 156, 741-766.

Kahan, D. M. (2007). The cognitively illiberal state. Stanford Law Review, 60, 115-54.

Kahan, D. M. and Braman, D. (2006). Cultural cognition and public policy. Yale Law \& Policy Review, Vol. 24, p. 147, 2006.

Kahan, D. M., Braman, D., Gastil, J., Slovic, P., \& Mertz, C. K. (2007). Culture and identityprotective cognition: Explaining the white-male effect in risk perception. Journal of Empirical Legal Studies, 4(3), 465-505.

Kahan, D., Braman, D., Monahan, J., Callahan, L. \& Peters, E. (In press). Cultural cognition and public policy: the case of outpatient commitment laws, Law \& Human Behavior. Advanced publication at http://dx.doi.org/10.1007/s10979-008-9174-4.

Kahan, D. M., Braman, D., Slovic, P., Gastil, J., \& Cohen, G. (2009). Cultural cognition of the risks and benefits of nanotechnology. Nature Nanotechnology, 4(2), 87-91.

Kahan, D. M., Hoffman, D. A., \& Braman, D. (2009). Whose eyes are you going to believe?



Kahan, D. M., Slovic, P., Braman, D., \& Gastil, J. (2006). Fear of democracy: A cultural critique of Sunstein on risk. Harvard Law Review, 119, 1071-1109.

Kahneman, D. (2003). Maps of bounded rationality: Psychology for behavioral economics. American Economic Review, 93(5), 1449-1475.

Kahneman, D., Slovic, P., \& Tversky, A. (1982). Judgment under uncertainty: Heuristics and biases. Cambridge ; New York: Cambridge University Press. 
Kasperson, R. E., \& Kasperson, J. X. (1996). The social amplification and attenuation of risk. Annals of the American Academy of Political and Social Science, 545, 95-105.

Kaufman, M. (2006, June 9). FDA approves vaccine that should prevent most cervical cancers. Washington Post, p. A1.

Kuran, T., \& Sunstein, C. R. (1998). Availability cascades and risk regulation. Stanford Law Review, 51, 683-768.

Lessig, L. (1995). The regulation of social meaning. University of Chicago Law Review, 62, 9431045.

Lord, C. G., Ross, L., \& Lepper, M. R. (1979). Biased assimilation and attitude polarization effects of prior theories on subsequently considered evidence. Journal of Personality and Social Psychology, 37(11), 2098-2109.

Lupia, A. (2002). Who can persuade whom?: Implications from the nexus of psychology and rational choice theory. In J. H. Kuklinski (Ed.), Thinking about political psychology (pp. 5188). Cambridge, England: Cambridge University Press.

MacCoun, R. J. (1998). Biases in the interpretation and use of research results. Annual Review of Psychology, 49, 259-287.

Mackie, D. M., \& Quellar, S. (2000). The impact of group membership on persuasion: Revisiting "who says what to whom with what effect?" In D. J. Terry, \& M. A. Hogg (Eds.), Attitudes, behavior, and social context: The role of norms and group membership (pp. 135-55). Mahwah, NJ: Lawrence Erlbaum Associate Publishers.

Margolis, H. (1996). Dealing with risk: Why the public and the experts disagree on environmental issues. Chicago, IL: University of Chicago Press. 
Marris, C., Langford, I. H., \& O'Riordan, T. (1998). A quantitative test of the cultural theory of risk perceptions: Comparison with the psychometric paradigm. Risk Analysis, 18(5), 635647.

McCrocsky, J. C. \& Young, T.J. (1981). Ethos and credibility: The construct and its measurement after three decades, 32 Central States Speech Journal, 32, 24-34.

National Conference of State Legislatures (2009). HPV Vaccine: State Legislation. Available at http://www.ncsl.org/programs/health/HPVvaccine.htm (checked October, 10, 2009).

National Organization of Women (2006, June 8). NOW applauds the FDA for approving the first vaccine for cervical cancer. http://www.now.org/press/06-06/06-08a.

Peters, E. M., Burraston, B., \& Mertz, C. K. (2004). An emotion-based model of risk perception and stigma susceptibility: Cognitive appraisals of emotion, affective reactivity, worldviews, and risk perceptions in the generation of technological stigma. Risk Analysis, 24(5), 13491367.

Peters, E., \& Slovic, P. (1996). The role of affect and worldviews as orienting dispositions in the perception and acceptance of nuclear power. Journal of Applied Social Psychology, 26(16), $1427-1453$.

Philipson, T. J., \& Posner, R. A. (1993). Private choices and public health: The AIDS epidemic in an economic perspective. Cambridge, Mass.: Harvard University Press.

Pidgeon, N. F., Kasperson, R. E., \& Slovic, P. (2003). The social amplification of risk. Cambridge ; New York: Cambridge University Press.

Pollock, A. (2005). Same-sex marriage would harm children. In K. Burns, \& H. Conrath (Eds.), Gay marriage (pp. 45-53). Detroit: Greenhaven Press. 
Pornpitakpan, C. (2004). The Persuasiveness of Source Credibility: A Critical Review of Five Decades' Evidence. Journal of Applied Social Psychology, 34 (2), 243-281.

Rayner, S. (1992). Cultural theory and risk analysis. In S. Krimsky, \& D. Golding (Eds.), Social theories of risk (pp. pp. 83-115). Westport, Conn.: Praeger.

Rosenthal, E. (2008, August 20). Drug makers' push leads to vaccines' fast rise. New York Times. (Late Edition), p. A1.

Saul, S., \& Pollack, A. (2007, Feb. 17). Furor on rush to require cervical cancer vaccine. New York Times. Retrieved from http://www.nytimes.com/2007/02/17/health/17vaccine.html.

Schkade, D., Sunstein, C. R., \& Hastie, R. (2007). What happened on deliberation day? California Law Review, 95(3), 915-940.

Siegel, R. B. (2007). The new politics of abortion: An equality analysis of woman-protective abortion restrictions. Illinois Law Review, 3, 991-1029.

Siegrist, M, Cvetkovich, C \& Roth, C. (2000). Salient value similarity, social trust, and risk/benefit perception, Risk Analysis 20(3), 353-362.

Slovic, P. (2000). The perception of risk. London ; Sterling, VA: Earthscan Publications.

Slovic, P., Finucane, M.L., Peters, E. \& MacGregor, D.G. (2004). Risk as analysis and risk as feelings: Some thoughts about affect, reason, risk, and rationality. Risk Analysis. 24(2), 311322.

Slovic, P., Flynn, J. H., \& Layman, M. (1991). Perceived risk, trust, and the politics of nuclear waste. Science, 254(5038), 1603-1607.

Starr, C. (1969). Social benefit versus technological risk. Science, 165(3899), 1232-1238.

Sunstein, C. R. (2005). Laws of fear: Beyond the precautionary principle. Cambridge, UK ; New York: Cambridge University Press. 
Sunstein, C. R. (2006). Misfearing: A reply. Harvard Law Review, 119(4), 1110-1125.

Thompson, M., Ellis, R., \& Wildavsky, A. (1990). Cultural theory. Boulder Colo.: Westview Press.

Viscusi, W. K. (1983). Risk by choice: Regulating health and safety in the workplace. Cambridge, Mass.: Harvard University Press.

Wildavsky, A., \& Dake, K. (1990). Theories of risk perception: Who fears what and why? Daedalus, 114, 41-60. 
Appendix. Information on On-line Sample

\section{Knowledge Networks}

Knowledge Networks and who participated in study experiments via Knowledge Network's on-line testing facilities. Knowledge Networks

(http://www.knowledgenetworks.com/) is a public opinion research firm with offices located throughout the United States. It maintains an active respondent pool of some 40,000 persons who are recruited to participate in on-line surveys and experiments administered on behalf of academic and governmental researchers and private businesses. Its recruitment and sampling methods assure a diverse sample that is demographically representative of the U.S. population (http://www.knowledgenetworks.com/ganp/reviewer-info.html). Studies using Knowledge Networks facilities are routinely published in peer-reviewed academic journals (http://www.knowledgenetworks.com/ganp/docs/KN\%20Bibliography\%20and\%20Journals\%20 List\%20-\%203-2-09.pdf).

2. Demographic composition of sample for this study

a. Total number of subjects: 1,538 .

b. Gender: $52 \%$ female, $48 \%$ male.

c. Race: $73 \%$ white, $10 \%$ African-American, $12 \%$ Hispanic, $5 \%$ other.

d. Average age: 47 years.

e. Median household income: $\$ 40,000$ to $\$ 49,999$.

f. Median education level: Some college. 


\section{Footnotes}

${ }^{1}$ Mandatory programs would make proof of vaccination (offered at state expense) a condition of school enrollment. Such programs, however, typically would allow for an "opt out" on religious or health grounds. One state, New Hampshire, sponsors a "voluntary" program in which vaccination is not a condition of school enrollment and interested parents must "opt in" to obtain their daughters' vaccination (National Conference of State Legislatures 2009).

${ }^{2}$ For functionalist accounts, in which individuals are seen as forming risk perceptions congenial to their ways of life precisely because holding those beliefs about risk cohere with and promote their ways of life, see Douglas, 1986; Thompson, Ellis \& Wildavsky 1990.

3 The "biased assimilation" dynamic — that people evaluate information in a manner that conforms their priors - is thought to be more strongly supported by empirical research than is the polarization dynamic - that disagreement among persons of opposing priors or predispositions grows when they are exposed to arguments (MacCoun, 1998; Gerber \& Green, 1999).

${ }^{4}$ More information on Knowledge Networks and the sample used for this study can be found in the Appendix.

5 Data on other individual characteristics - including gender, race, and liberalconservative ideology-were also collected. However, we did not plan to include those characteristics as covariates in the analyses for several reasons. First, because the subjects were randomly assigned to experimental conditions, these characteristics were properly treated as ignorable for purposes of testing hypothesized differences across the conditions (Gelman \& Hill, 
2007, 183). Second, previous studies of the influence of cultural cognition have consistently found that cultural worldviews more strongly predict risk perceptions than do other individual characteristics, many of which explain variance in risk perception only because they correlate or interact with cultural worldviews (Kahan et al., 2007; Kahan et al., in press). Third, the cultural credibility hypothesis contemplated that subjects would be influenced by advocates conditional on affinity between their own and the advocates' perceived cultural values; we did not formulate hypotheses on the credibility differences of culturally identifiable advocates across subjects identified by other characteristics. Finally, testing any such hypotheses simultaneously with the testing of hypotheses about the effect of the affinity between subjects' values and advocates' perceived values (which would have necessitated additional interaction terms for the experimental treatments and each additional covariate) would necessarily have demanded a substantial increase in sample size in order to assure sufficient power to rule out type 2 errors (Gelman \& Hill, 2006, p. 438; Cohen, Cohen, West \& Aiken, 2003, p. 297).

${ }^{6}$ As particular instances of the general linear model, MRC and analysis of variance generate functionally equivalent measures for assessing experimental results (Cohen, Cohen, West \& Aiken, 2003, pp. 4-5). MRC, however, permits straightforward linear estimation of the explanatory or predictive effect of continuous measures, which in ANOVA are typically converted into discrete categorical predictors through median-splits or like sample divisions. The latter procedure results in a substantial reduction in statistical power, a consideration particularly important for our study. The "biased assimilation" and "cultural credibility" hypotheses made predictions about the joint effects of the worldview predictors, which treated as continuous 
measures could be tested with the entire sample through MRC, but which would have required comparisons of sub-groups ("hierarchical individualists" and "egalitarian communitarians"), each consisting of approximately only one-fourth of the total sample, to be tested with ANOVA. In addition, using ANOVA after converting continuous measures into categorical ones can also result in biased estimates because of the sensitivity of the results to the exact location of the point or points at which the continuous predictor is split (Maxwell \& Delaney, 1993). 
